\title{
Prevalence of respiratory symptoms, features of asthma, and characteristics associated with respiratory disease, in 6-11 year olds in Manchester
}

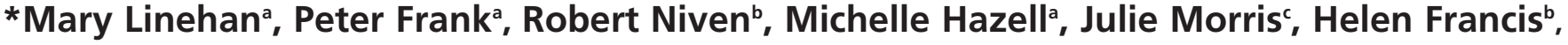 Timothy Frank ${ }^{a}$}

${ }^{a}$ GP Research Unit, North West Lung Research Centre, Wythenshawe Hospital, Manchester, UK

${ }^{b}$ North West Lung Research Centre, Wythenshawe Hospital, Manchester, UK

'Department of Medical Statistics, University Hospital of South Manchester NHS Foundation Trust, Manchester, UK

Received 7th November 2007; resubmitted 9th January 2008; final revised version received 19th April 2008; accepted 11th May 2008; online 9th July 2008

\begin{abstract}
Aims: This paper describes the prevalence of respiratory symptoms, features of asthma, and characteristics associated with respiratory disease in 6-11 year old children in an historical cohort study.

Methods: The study included 5086 children, all born in the same maternity unit in the north west of England over a four-year period. The prevalence of respiratory symptoms, features of asthma, and characteristics associated with respiratory disease were determined by the use of parent-completed questionnaires. Skin prick tests were used to ascertain atopic status.

Results: The response was $47.5 \%$. The prevalence of wheeze, asthma medication use and atopic sensitisation were $20.3 \%, 16.2 \%$ and $37.1 \%$ respectively. Wheeze and atopy were significantly more prevalent in boys $(22.4 \%$ versus $17.9 \%$ and $43.0 \%$ versus $29.3 \%$, respectively).

Conclusions: This study identified a high prevalence of respiratory disease in this population and provides a baseline for monitoring trends in respiratory disease in 6-11 year old children.

(C) 2009 General Practice Airways Group. All rights reserved

M Linehan, et al. Prim Care Resp J 2009; 18(1): 21-26.

doi:10.3132/pcrj.2008.00041
\end{abstract}

Keywords atopy, prevalence, children, respiratory, wheeze, asthma, medication use

The full version of this paper, with online Appendix A is available online at www.thepcrj.org

\section{Introduction}

Asthma is one of the most common childhood diseases in Britain ${ }^{1}$ and its prevalence has increased considerably over recent decades ${ }^{2-4}$ although recent evidence suggests that it has now stabilised. ${ }^{5}$ However, interpretation of data in childhood asthma has been problematic because of disparities in the definitions used, differences between populations studied, and different study methodologies.

These problems have been partially overcome in recent years following the International Study of Asthma and Allergy in Childhood (ISAAC) study which used a uniform method for comparing prevalence of asthma and atopic disease within and between countries. ${ }^{6}$ Nevertheless, identification of trends remains difficult when prevalence is being compared between different age groups and different populations.

The Manchester Community Asthma Study (MANCAS) investigated the prevalence of asthma and atopy in 6-11 year old children in a major city in the north, west of England as part of an investigation into the possible association between neonatal BCG vaccination and asthma/atopy. The results of that study have been reported elsewhere.? This paper uses data from the MANCAS study to describe the prevalence of respiratory symptoms, features of asthma, and characteristics

*Corresponding author: Dr Mary Linehan, North West Lung Research Centre, GP Research Unit, Wythenshawe Hospital, Southmoor Road, Manchester, M23 9LT, UK. Tel: 01612915044 Fax: 01612915047 Email: linehanmary@yahoo.co.uk 
M Linehan et al.

\begin{tabular}{|c|c|c|c|c|c|c|c|c|c|}
\hline \multirow[b]{2}{*}{$\%$ Male $(n)$} & \multirow{2}{*}{$\begin{array}{l}\text { Non responders } \\
\quad(n=2672)\end{array}$} & \multicolumn{2}{|c|}{$\begin{array}{l}\text { Responders } \\
(n=2414)\end{array}$} & \multirow{2}{*}{$\begin{array}{c}\text { p value } \\
\text { (responders vs } \\
\text { non responders }\end{array}$} & \multicolumn{2}{|c|}{$\begin{array}{l}\text { Skin prick } \\
\text { tested } \\
(n=949)\end{array}$} & \multicolumn{2}{|c|}{$\begin{array}{c}\text { Not skin } \\
\text { prick tested } \\
(n=1465)\end{array}$} & \multirow{2}{*}{$\begin{array}{c}\begin{array}{c}\mathrm{p} \text { value } \\
\text { (tested vs } \\
\text { not tested }\end{array} \\
0.006\end{array}$} \\
\hline & & $53.6 \%$ & (1295) & & $56.9 \%$ & $(540)$ & $51.5 \%$ & $(755)$ & \\
\hline $\begin{array}{l}\text { Mean age in days } \\
\text { (SD) at first mailing }\end{array}$ & $2453 \quad(383.5)$ & 2488 & $(390.0)$ & 0.001 & 2492 & $(388.4)$ & 2485 & (391.2) & 0.7 \\
\hline \% Wheeze $(n)$ & - & . & & - & $24.2 \%$ & (229) & $17.9 \%$ & $(261)$ & $<0.001$ \\
\hline
\end{tabular}

Table 2. Prevalence of respiratory symptoms, features of asthma, and characteristics associated with respiratory disease, with gender differences and associated odds ratios (OR) and $95 \%$ confidence intervals $(\mathrm{CI})$.

\begin{tabular}{|c|c|c|c|c|c|c|}
\hline Symptoms & & otal \% (n) & Boys \% (n) & Girls $^{\dagger} \%(n)$ & OR $[95 \% \mathrm{Cl}]$ & $\mathrm{p}$ for $\mathrm{chi}^{2}$ test \\
\hline Night cough* & 33.5 & $(799 / 2387)$ & $32.8(421 / 1282)$ & $34.2(378 / 1105)$ & $0.94[0.79-1.12]$ & 0.48 \\
\hline \multicolumn{7}{|l|}{ Features of asthma } \\
\hline Asthma attack* & 9.3 & $(220 / 2377)$ & $10.2(130 / 1274)$ & $8.2 \quad(90 / 1103)$ & $1.28 \quad[0.97-1.70]$ & 0.09 \\
\hline \multicolumn{7}{|c|}{ Characteristics of respiratory disease } \\
\hline Hayfever/eczema & 38.8 & $(918 / 2369)$ & $40.4 \quad(512 / 1268)$ & $36.9(406 / 1101)$ & 1.16 [0.98-1.37] & 0.08 \\
\hline Family history asthma & 59.6 & $(1415 / 2374)$ & $59.8 \quad(762 / 1275)$ & $59.4 \quad(653 / 1099)$ & 1.02 [0.86-1.19] & 0.86 \\
\hline 1 or more smokers in household & 46.3 & $(1052 / 2271)$ & $45.2(553 / 1223)$ & $47.6 \quad(499 / 1048)$ & 0.91 [0.77-1.07] & 0.25 \\
\hline$>3$ courses antibiotics ${ }^{*}$ & 10.9 & $(260 / 2387)$ & $10.8(138 / 1282)$ & $11.0 \quad(122 / 1105)$ & $0.97 \quad[0.75-1.26]$ & 0.82 \\
\hline
\end{tabular}

associated with respiratory disease in this population of children. The purpose of this paper is to contribute to the surveillance of respiratory disease prevalence and to facilitate comparisons with other children in similar age groups.

\section{Method}

The study population consisted of 5086 children, all born in the same maternity unit between 1st July 1993 and 31st March 1997. Parent-completed questionnaires were used to identify respiratory symptoms, features of asthma, and characteristics associated with respiratory disease. Questionnaires and study information leaflets were sent over a 21-month period (July 2002 to March 2004), and approximately 100 were posted on a phased weekly basis in chronological order with the oldest children in the study being selected first. The questionnaire (see Appendix A, available online at www.thepcrj.org), a modified version of the ISAAC core questionnaire for wheezing and asthma, ${ }^{6}$ was based on that used in the Wythenshawe Community Asthma Project (WYCAP). ${ }^{8}$ Reminders were sent to non-responders after four and eight weeks and at the end of the distribution period. The return of a completed questionnaire was considered as consent to participate in the study. Responders to the questionnaire were invited to participate in skin prick tests to identify atopic sensitisation.

\section{Skin Testing}

The study rationale and the skin prick test procedure were explained to parents and children and they were given an opportunity to ask questions. Parental signed consent and the child's verbal assent were then obtained prior to the skin prick test procedure. Children participating in the skin prick test phase of the study were tested for sensitisation to house dust mite, cat, dog, grass and Alternaria using Alk Abello antigen solutions. The skin prick test was carried out on the volar aspect of the child's forearm in a standardised manner. ${ }^{9}$ Histamine was used as the positive control and a solution of saline as the negative control. Test results were read after 15 minutes and were calculated as the mean of the longest diameter and the diameter perpendicular to it. A reaction was considered positive if the mean wheal diameter was $\geq 3 \mathrm{~mm}$ larger than the negative control.

\section{Statistical methods}

Analyses were performed using SPSS for Windows software. ${ }^{10}$ Responses to the questionnaire were examined in univariate 
Table 3. Frequency and features of wheeze with gender differences and associated odds ratios (OR) and $95 \%$ confidence intervals $(\mathrm{Cl})$.

\begin{tabular}{|c|c|c|c|c|c|c|c|c|}
\hline \multirow{2}{*}{$\begin{array}{l}\text { Wheeze } \\
\text { No attacks of wheezing* }+\end{array}$} & \multicolumn{2}{|c|}{ Total \% (n) } & \multicolumn{2}{|c|}{ Boys \% (n) } & \multicolumn{2}{|c|}{ Girlst \% (n) } & OR $[95 \% \mathrm{Cl}]$ & \multirow{2}{*}{$\frac{p \text { for } \text { chi }^{2} \text { test }}{0.56}$} \\
\hline & 11.9 & $(56 / 471)$ & 11.2 & $(31 / 278)$ & 13.0 & $(25 / 193)$ & $0.84 \quad[0.48-1.48]$ & \\
\hline 1-3 attacks of wheezing* & 55.2 & $(260 / 471)$ & 55.0 & $(153 / 278)$ & 55.4 & $(107 / 193)$ & $0.98 \quad[0.68-1.42]$ & 0.93 \\
\hline 4-12 attacks of wheezing* & 24.8 & $(117 / 471)$ & 24.8 & $(69 / 278)$ & 24.9 & $(48 / 193)$ & 0.99 [0.65-1.53] & 0.99 \\
\hline$>12$ attacks wheezing* & 8.1 & $(38 / 471)$ & 9.0 & $(25 / 278)$ & 6.7 & $(13 / 193)$ & $1.37 \quad[0.68-2.75]$ & 0.38 \\
\hline Speech limiting wheeze* & 20.6 & $(97 / 470)$ & 22.8 & $(64 / 281)$ & 17.5 & $(33 / 189)$ & 1.39 [0.87-2.23] & 0.16 \\
\hline Wheeze with exercise* & 68.6 & $(325 / 474)$ & 66.2 & $(188 / 284)$ & 72.1 & $(137 / 190)$ & $0.76 \quad[0.51-1.13]$ & 0.18 \\
\hline
\end{tabular}

analyses to identify the prevalence of respiratory symptoms, features of asthma, and characteristics associated with respiratory disease. The severity of wheeze amongst those children reported to have wheezed in the past 12 months was also examined. Atopic sensitisation was investigated and the prevalence of sensitisation to each aeroallergen tested was identified. Prevalence was stratified by gender to identify important differences in risk and/or burden of disease. The statistical significance of differences in proportions was assessed using chi-squared tests and odds ratios with 95\% confidence intervals. Differences in means were examined using t-tests, and logistic regression analyses were used to adjust for potential confounders of the associations between symptoms and disease characteristics.

South Manchester Local Research Ethics Committee approved the MANCAS study.

\section{Results}

The study population consisted of 5086 children $(52.1 \%$ male). There were 2414 questionnaire responses (53.6\% male), a response rate of $47.5 \%$. The mean age was 7.3 years (range 6 to 11 years) and $46.3 \%$ of the children lived in a household with one or more smokers.

Amongst responders, 949 children (39.3\%) had a skin prick test for atopic sensitisation performed.

Table 1 shows the known characteristics of the study population. The proportion of male responders was significantly higher than the proportion of male nonresponders $(53.6 \%$ versus $50.7 \%, p=0.04)$ and nonresponders were younger than responders (mean age 2453 days versus 2488 days, $p=0.001$ ). Children who had a skin prick test were more likely to be male and to have wheezed in the past 12 months ( $p=0.006$ and $p<0.001$ respectively).

Table 2 shows the prevalence of respiratory symptoms, features of asthma, and characteristics associated with respiratory disease. One-fifth $(20.3 \%)$ of the study participants reported wheeze in the past 12 months and this prevalence was significantly higher in boys (odds ratio (OR) $1.33,95 \%$ confidence interval (CI) 1.08-1.62). There were no other significant gender differences. The prevalence of night cough was high at $33.5 \%$, and the most common associated characteristic was a family history of asthma reported by almost $60 \%$ of the responders. Over one-third of the children had a history of hay fever/eczema.

Children for whom wheezing in the past 12 months was reported were asked to respond to related questions on the nature and frequency of wheeze. The responses, stratified by gender, are shown in Table 3. Of the 490 children for whom wheezing was reported, 471 responded to a related question on the number of attacks of wheezing in the previous 12 months; $11.9 \%$ reported none, over half of the children $(55.2 \%)$ had between one and three attacks of wheezing, almost a quarter (24.8\%) had between four and 12 attacks, and $8.1 \%$ had suffered $>12$ attacks of wheezing in the past 12 months. One-fifth (20.6\%) of the 470 respondents to question 4 had experienced wheeze severe enough to limit speech. Out of 475 respondents, almost half $(47.8 \%)$ were woken by an attack of wheezing in the past 12 months. Wheeze was associated with exercise for over twothirds $(68.6 \%)$ of the 474 respondents to a question on exercise-related wheeze. There were no statistically significant gender differences in the frequency or characteristics of wheeze.

The association between respiratory symptoms/features of asthma and each characteristic associated with asthma, after adjustment for gender and for the other characteristics, is shown in Table 4. There was a statistically significant increase in risk of wheeze and night cough for children for whom any of the associated characteristics was reported. Having suffered an asthma attack in the past 12 months, or having used asthma medication was significantly associated with having had $>3$ courses of antibiotics for chest, ear or throat 
M Linehan et al.

\begin{tabular}{|c|c|c|c|c|}
\hline \multirow[b]{2}{*}{ Symptom/feature of asthma } & \multicolumn{4}{|c|}{ Characteristics associated with respiratory disease } \\
\hline & $\begin{array}{c}>3 \text { courses } \\
\text { antibiotics* }\end{array}$ & $\begin{array}{l}\text { Hay fever } \\
\text { or eczema }\end{array}$ & $\begin{array}{c}\text { Family history } \\
\text { of asthma }\end{array}$ & $\begin{array}{c}\geq 1 \text { smoker in } \\
\text { household }\end{array}$ \\
\hline Wheeze & $3.79 \quad[2.80-5.13]$ & $2.79 \quad[2.22-3.50]$ & $2.27[1.76-2.93]$ & $1.27 \quad[1.01-1.59]$ \\
\hline Night cough & $3.70 \quad[2.75-4.98]$ & $2.20 \quad[1.82-2.67]$ & $1.81[1.48-2.21]$ & 1.45 [1.20-1.75] \\
\hline Asthma attack & $3.94 \quad[2.75-5.64]$ & $2.94 \quad[2.13-4.07]$ & 1.91 [1.33-2.73] & $0.78 \quad[0.57-1.07]$ \\
\hline Asthma medication & $3.22 \quad[2.34-4.41]$ & 3.15 [2.45-4.04] & $2.20[1.66-2.92]$ & $0.97 \quad[0.76-1.24]$ \\
\hline
\end{tabular}

*in past 12 months; ₹ for chest, ear or throat problems

Table 5. Atopic sensitisation with gender differences and associated odds ratios (OR) and $95 \%$ confidence intervals (CI).

\begin{tabular}{|c|c|c|c|c|c|c|c|c|}
\hline \multirow[b]{2}{*}{ Atopic } & \multicolumn{2}{|c|}{ Total \% (n) } & \multicolumn{2}{|c|}{ Boys \% (n) } & Girlst \% (n) & \multicolumn{2}{|c|}{ OR $[95 \% \mathrm{Cl}]$} & \multirow{2}{*}{$\frac{p \text { for } \mathrm{chi}^{2} \text { test }}{<0.01}$} \\
\hline & 37.1 & (352/949) & 43.0 & $(232 / 540)$ & $29.3 \quad(120 / 409)$ & 1.81 & [1.38-2.38] & \\
\hline House dust mite & 25.1 & $(238 / 949)$ & 28.9 & $(156 / 540)$ & $20.0 \quad(82 / 409)$ & 1.62 & [1.19-2.20] & $<0.01$ \\
\hline Cat & 12.1 & $(115 / 949)$ & 13.7 & $(74 / 540)$ & $10.0 \quad(41 / 409)$ & 1.43 & {$[0.95-2.14]$} & 0.09 \\
\hline Dog & 7.9 & $(75 / 949)$ & 9.6 & $(52 / 540)$ & $(23 / 409)$ & 1.79 & {$[1.08-2.98]$} & 0.02 \\
\hline
\end{tabular}

† Reference group; N/A Not applicable due to small numbers

Table 6. Prevalence of respiratory symptoms and features of asthma by atopic status with odds ratios (OR) and 95\% confidence intervals (CI).

\begin{tabular}{|c|c|c|c|c|}
\hline & $\%(n)$ with resp & atory symptoms & Adjusted OR $[95 \% \mathrm{Cl}]$ & $\mathrm{p}$ for $\mathrm{chi}^{2}$ test \\
\hline Wheeze in the past 12 months* & $(147 / 352)$ & $(82 / 595)$ & 3.63 [2.54-5.17] & $<0.001$ \\
\hline Night cough in the past 12 months* & $49.3(171 / 347)$ & $30.3(179 / 590)$ & $2.07 \quad[1.51-2.83]$ & $<0.001$ \\
\hline Asthma attack in the past 12 months* & $21.8 \quad(75 / 344)$ & $(34 / 588)$ & $3.47 \quad[2.15-5.58]$ & $<0.001$ \\
\hline Asthma medication* & $35.8 \quad(125 / 349)$ & $(64 / 594)$ & $3.54 \quad[2.44-5.14]$ & $<0.001$ \\
\hline
\end{tabular}

*adjusted for gender, household smoking, >3 courses antibiotics, history hay fever/eczema and family history of asthma

problems, with a history of hay fever or eczema and with a family history of asthma.

Table 5 shows the prevalence of atopic sensitisation. Over one third of the children tested were sensitised to at least one of the aeroallergens examined. Boys were significantly more likely to be sensitised than girls (OR 1.81, 95\% CI 1.38-2.38), and allergy to house dust mite, dog and grass was significantly more common among boys whilst there were no statistically significant gender differences for cat allergy. Only four children were sensitised to Alternaria.

Symptoms and features of asthma were significantly more common among atopic children than non-atopic children (Table 6).

\section{Disaussion}

This paper describes the prevalence of respiratory symptoms, features of asthma, and characteristics associated with respiratory disease, in 6-11 year olds in the north west of England. The questionnaire used contained the core ISAAC questions for respiratory symptoms in the previous 12 months ${ }^{6}$ and was based on the WYCAP questionnaire. The WYCAP questionnaire has been validated for use in children aged between 5 and 15 years. ${ }^{8}$ Skin prick tests were carried out to identify the prevalence of atopic sensitisation.

The $47.5 \%$ response rate was lower than had been anticipated at the outset of the study. The letter accompanying the questionnaire stated that the study was investigating 
asthma and allergy in children and although it did state that responses from children who did not have asthma or allergies were also important, this emphasis may have influenced potential participants' perception of the study and its relevance to them. Evidence that parents of children with respiratory symptoms may have been more inclined to respond was suggested by the higher number of male responders compared to non-responders, given that the prevalence of respiratory symptoms is said to be higher in boys." ${ }^{11}$

The study team was unknown to the study population and this might have influenced inclination to participate, although a steady decline in response rates was also noted in WYCAP studies even though the questionnaires were accompanied by a letter from the recipient's GP practice. ${ }^{12,13}$ Decreasing response rates were also reported in other community studies in the UK and worldwide ${ }^{14-16}$ and so it may be that the low response rate in this study reflects current attitudes to research participation rather than sample bias.

A possible explanation for the finding that nonresponders were likely to be younger than responders is that the questionnaires were sent out over a 21-month period with the oldest children receiving their questionnaire first; consequently, parents of older children will have received their questionnaire closer to the time that they were informed of the study. Males and children who (according to the MANCAS study definition) had asthma and/or wheezing were more likely to have participated in the skin prick test phase of the study. The higher participation rate in the skin prick test phase of males and children with respiratory symptoms might, again, reflect a greater tendency amongst parents of children with respiratory symptoms to participate in the study.

Thus, a limitation of this study may be the increased participation of children with respiratory and/or atopic symptoms leading to an overestimation of prevalence in this population. However, although this study reports a high prevalence of respiratory disease in children in Manchester, it is not dissimilar to prevalences detected in other studies in the UK. Studies in the north east of England reported a prevalence of $18.0 \%$ for wheeze in the past 12 months, $27.7 \%$ for night cough and $22.7 \%$ for asthma in $6-7$ year olds $^{17}$ and respective prevalences of $19.9 \%, 20.4 \%$ and $22.3 \%$ for $13-14$ year olds. ${ }^{18}$ In a study of 10 year olds on the Isle of Wight, the 12-month prevalence of wheeze was $18.9 \%{ }^{19}$ and a study in the south of England also reported prevalence of $18.9 \%$ for wheeze in the past 12 months and $25.3 \%$ for night cough in 7-9 year olds. ${ }^{20}$ The WYCAP study, carried out in one area of Manchester, included children up to the age of 15 years and, from a 2001 survey, reported a prevalence of $22 \%$ for wheeze in the previous 12 months, $25 \%$ for night cough and $19 \%$ for asthma. ${ }^{12}$ Phase 3 of the
ISAAC study reported a prevalence of $20.9 \%$ for wheeze in 6-7 year olds and $24.7 \%$ in $13-14$ year olds in the UK.21

Although the age of children in this study ranged from 6 -11 years, age-specific prevalences were not calculated since $92 \%$ of the children were either seven or eight years old at the time of questionnaire response so stratification by age was inappropriate.

The higher prevalence of wheeze in boys noted in this study was in keeping with gender differences reported for children in similar age groups in other studies. 19,22,23 There were no statistically significant gender differences in the severity of wheeze, suggesting that although boys are more likely to wheeze than girls, amongst children who do experience wheeze severity is similar in both males and females.

Over $10 \%$ of the children had more than three courses of antibiotics in the preceding 12 months and the risk of wheeze, night cough, asthma attack and asthma medication was greatest for these children. This might reflect an increased risk of asthma in children who suffer repeated respiratory tract infections, an increased risk of respiratory infections in children with asthma, or alternatively might reflect inappropriate antibiotic prescribing for children presenting to general practitioners with asthma symptoms. ${ }^{24,25}$

Atopy and a family history of asthma are established risk factors for asthma, ${ }^{26,27}$ supporting the increased risk identified for these factors in this study.

Almost half $(46.3 \%)$ of the children lived in a household with smokers. Living with one or more smokers was associated with an increased risk of wheeze and night cough in this study. Previously reported associations between smoking and doctordiagnosed asthma have been limited to certain subgroups. An Italian study only identified an increased risk of asthma for children if 40 or more cigarettes are smoked per day in the home and only in one of three surveys in the study. ${ }^{28}$ Maternal but not paternal smoking was significantly associated with asthma in UK studies. ${ }^{17,29}$ However, several studies identified significant associations between wheeze and exposure to cigarette smoke ${ }^{17,18,20,22}$ and it may be that even if exposure to cigarette smoke does not directly cause asthma, it does increase expression of respiratory symptoms.

The prevalence of atopic sensitisation in this study was higher than that identified in another UK study where the prevalence amongst 10 year olds was $26.9 \%^{30}$ but much lower than the $62.7 \%$ reported in a UK study of 7-14 year olds, all of whom had asthma. ${ }^{31}$

An advantage of the MANCAS study was its large population of children, all born in the same hospital but living in various areas of a large city with diverse socio-economic and social groups. Also, the children were all aged at least six years old at the time of their participation in the study; this increases the likelihood that symptoms were related to 
asthma, since wheezing in children younger than five years old might indicate other wheezing illnesses.

This study identified a high prevalence of respiratory symptoms, and characteristics commonly associated with respiratory disease in children were observed. Similar high prevalences have been reported in other UK studies. Thus, it would appear that despite the low response rate, this study is comparable with other UK studies and can, in the current climate of declining response rates, provide a baseline for monitoring future trends in the prevalence of respiratory diseases in schoolchildren.

\section{Conflict of interest dedaration}

Dr M Linehan received a British Thoracic Society/Schering-Plough Travel Fellowship bursary of $f 750$ in 2003. Dr P Frank has no conflict of interest. Dr R Niven has no conflict of interest. Dr M Hazell received a British Thoracic Society/Schering-Plough Travel Fellowship bursary of $f 750$ in 2002, a fee for speaking from Boehringer Ingelheim and honoraria for providing training in evidence based practice and research methods for Education for Health. J M orris has no conflict of interest. $\mathrm{Dr} \mathrm{H}$ Francis received a travel grant from Novartis. Dr T Frank received fees from GSK, Boehringer Ingelheim, Schering Plough and AstraZeneca for speaking; funds for research from GSK, Boehringer Ingelheim, MSD and Schering Plough; funds for consultancy from GSK and Pharmacia and travel grants from GSK, Boehringer Ingelheim, AstraZeneca, Chiesi Pharmaceuticals and MSD.

\section{Funding}

The MANCAS study was funded by Asthma UK.

\section{References}

1. Panickar JR, Dodd SR, Smyth RL, Couriel JM. Trends in deaths from respiratory illness in children in England and Wales from 1968 to 2000. Thorax 2005; 60(12):1035-8. doi:10.1136/thx.2005.044750

2. Burr ML, Butland BK, King S, Vaughan-Williams E. Changes in asthma prevalence: two surveys 15 years apart. Arch Dis Child 1989;64(10):1452-6. doi:10.1136/adc.64.10.1452

3. Ninan TK, Russell G. Respiratory symptoms and atopy in Aberdeen schoolchildren: evidence from two surveys 25 years apart. $\mathrm{Br}$ Med J 1992; 304(6831):873-5.

4. Omran M, Russell G. Continuing increase in respiratory symptoms and atopy in Aberdeen schoolchildren. Br Med J 1996;312(7022):34.

5. Pearce N, Douwes J. The global epidemiology of asthma in children. Int J Tuberc Lung Dis 2006;10(2):125-32.

6. Asher MI, Keil U, Anderson HR, et al. International Study of Asthma and Allergies in Childhood (ISAAC): rationale and methods. Eur Respir J 1995; 8(3):483-91.

7. Linehan MF, Frank TL, Hazell ML, et al. Is the prevalence of wheeze in children altered by neonatal BCG vaccination? J Allergy Clin Immunol 2007; 119(5):1079-85. doi:10.1016/j.jaci.2006.12.672

8. Frank TL, Frank Pl, McNamee R, Wright T, Hannaford P, Morrison J, Hirsch S, Pickering CAC. Assessment of a simple scoring system applied to a screening questionnaire for asthma in children aged 5-15 yrs. Eur Respir J 1999;14:1190-7.

9. Linehan MF. Investigation of the prevalence of asthma and atopy in BCG vaccinated and BCG non-vaccinated cohorts of children in Central Manchester. PhD thesis. University of Manchester; Manchester. 2006

10. SPSS Inc. SPSS. 10.1.4 ed. Chicago: SPSS Inc.; 2001.

11. DeMeo DL, Weiss ST. Epidemiology. In: Barnes P, Drazen J, Rennard S, Thomson $\mathrm{N}$, editors. Asthma and COPD. London: Elsevier Science Ltd; 2002. p. 7-18.
doi:10.1016/B978-012079028-9/50077-6

12. Frank PI, Wicks PD, Hazell ML, et al. Temporal change in the prevalence of respiratory symptoms and obstructive airways disease 1993-2001. Br J Gen Pract 2005;55(517):596-602.

13. Linehan MF, Hazell ML, Frank TL, Frank PI. Prevalence of respiratory symptoms in under 5s: 1993 to 2001. Arch Dis Child 2005;90(5):516-9. doi:10.1136/adc.2004.061879

14. Office of National Statistics. General Household Survey 2004 - Appendix B; Sample design \& response. 2005 [cited 02/11/2007]; Available from: http://www.statistics.gov.uk/downloads/theme_compendia/03_Appendix_B.pdf

15. Asch DA, Jedrziewski MK, Christakis NA. Response Rates to Mail Surveys Published in Medical Journals. J Clin Epidemiol 1997;50 (10):1129-36. doi:10.1016/S0895-4356(97)00126-1

16. Brogger J, Nystad W, Cappelen I, Bakke P. No increase in response rate by adding a web response option to a postal population survey: a randomized trial. J Med Internet Res 2007;9(5):e40. doi:10.2196/jmir.9.5.e40

17. Shamssain MH, Shamsian N. Prevalence and severity of asthma, rhinitis, and atopic eczema: the north east study. Arch Dis Child 1999;81:313-17. doi:10.1136/adc.81.4.313

18. Shamssain $M H$, Shamsian $\mathrm{N}$. Prevalence and severity of asthma, rhinitis, and atopic eczema in 13- to 14-year-old schoolchildren from the northeast of England. Ann Allergy, Asthma Immunol 2001;86(4):428-32.

19. Kurukulaaratchy RJ, Fenn M, Twiselton R, Matthews S, Arshad SH. The prevalence of asthma and wheezing illnesses amongst 10-year-old schoolchildren. Respir Med 2002;96(3):163-9. doi:10.1053/rmed.2001.1236

20. Coleman H, McCann DC, McWhirter J, Calvert M, Warner JO. Asthma, wheeze and cough in 7-9 year old British schoolchildren. Ambulatory Child Health 2001;7(3-4):313-21. doi:10.1046/j.1467-0658.2001.00140.x

21. Asher Ml, Montefort S, Bjorksten B, et al. Worldwide time trends in the prevalence of symptoms of asthma, allergic rhinoconjunctivitis, and eczema in childhood: ISAAC Phases One and Three repeat multicountry cross-sectional surveys. Lancet 2006;368:733-43. doi:10.1016/S0140-6736(06)69283-0

22. Nicholson AJ, Harty SB, Howell F, Sheridan P. Wheeze, Eczema and Rhinitis in 6-7 year old Irish Schoolchildren. Ir Med J 2003;96(4):102-04.

23. Venn A, Lewis S, Cooper M, Hill J, Britton J. Questionnaire study of effect of sex and age on the prevalence of wheeze and asthma in adolescence. Br Med J 1998;316:1945-6.

24. Levy M, Bell L. General practice audit of asthma in childhood. Br Med J 1984; 289(6452):1115-18.

25. Levy M, Parmar M, Coetzee D, Duffy SW. Respiratory consultations in asthmatic compared with non-asthmatic children in general practice. $\mathrm{Br}$ Med J (Clin Res Ed) 1985;291(6487):29-30.

26. Crater SE, Platts-Mills TA. Searching for the cause of the increase in asthma. Curr Opin Pediatr 1998;10(6):594-9. doi:10.1097/00008480-199810060-00010

27. Jarvis D, Burney P. Epidemiology of Atopy and Atopic Disease. In: Kay AB, editor. Allergy and Allergic Diseases. Oxford: Blackwell Science; 1997. p. 1208-19.

28. Ronchetti R, Villa MP, Barreto $M$, et al. Is the increase in childhood asthma coming to an end? Findings from three surveys of schoolchildren in Rome, Italy. Eur Respir J 2001;17(5):881-6.

29. Delpisheh A, Kelly Y, Rizwan S, Brabin BJ. Salivary Cotinine, Doctor-diagnosed Asthma and Respiratory Symptoms in Primary Schoolchildren. Matern Child Health J. 2007. DOI 10.1007/s10995-007-0229-9.

30. Kurukulaaratchy RJ, Matthews S, Arshad SH. Defining childhood atopic phenotypes to investigate the association of atopic sensitization with allergic disease. Allergy 2005; 60(10):1280-6. doi:10.1111/j.1398-9995.2005.00890.x

31. Carroll WD, Lenney W, Child F, et al. Asthma severity and atopy: how clear is the relationship? Arch Dis Child 2006;91(5):405-09. doi:10.1136/adc.2005.08827 
Appendix A. Questionnaire

To be completed by the Parent or Guardian - Please tick the appropriate box

What is your child's date of birth?

Is your child

FEMALE

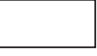

MALE

1. Has your child had wheezing or whistling in the chest in the last $\mathbf{1 2}$ months? IF ‘NO’ PLEASE GO TO QUESTION 7

2. How many attacks of wheezing has your child had in the last $\mathbf{1 2}$ months? None 1 to 3 4 to 12 More than 12

3. In the last $\mathbf{1 2}$ months, how often, on average, has your child's sleep been disturbed due to wheezing?

$$
\begin{aligned}
& \text { Never woken with wheezing } \\
& \text { Less than one night per week } \\
& \text { One or two nights per week } \\
& \text { More than } 2 \text { nights per week }
\end{aligned}
$$

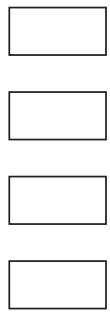

4. In the last $\mathbf{1 2}$ months, has wheezing ever been severe enough to limit your child's speech to only one or two words at a time between breaths?

5. Has your child been woken by an attack of wheezing in the last 12 months?

6. In the last 12 months, has your child's chest sounded wheezy during or after exercise?

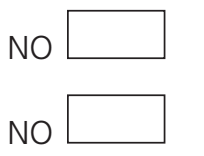

YES

YES

$\mathrm{NO}$

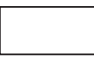

YES

$\mathrm{NO}$

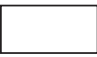

YES

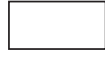
apart from a cough associated with a cold or chest infection

8. Has your child had more than 3 courses of antibiotics for respiratory infections (chest, ears or throat) in the last 12 months?

$\mathrm{NO}$

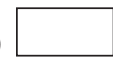

YES

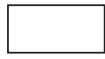

9. Is your child currently taking any medicine for asthma?

(including inhalers, aerosols or tablets)

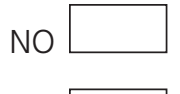

YES

10. Has your child had an attack of asthma in the last $\mathbf{1 2}$ months?

11. Has your child had hay fever or eczema

$\mathrm{NO}$

$\mathrm{NO}$

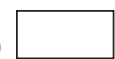

YES

YES

12. Has anyone in your child's family (parents, grandparents, sisters or brothers had asthma?

$\mathrm{NO}$

YES

13. How many adults live in your house?

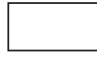

How many of these adults smoke?

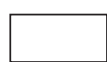

PLEASE TURN OVER 
M Linehan et al.

Appendix A. Questionnaire continued

14. How many children live in your house?

How many of these children are older than the child for whom you have answered this questionnaire?

15. What is your child's ethnic group?

Please tick as appropriate (listed in alphabetical order)

Bangladeshi

Black-African

Black-Caribbean

Black-other

Please describe

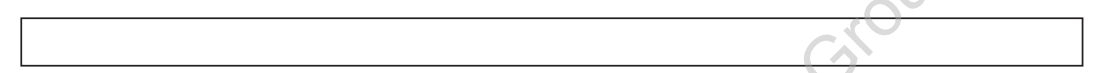

Chinese

Indian

Pakistani

White

Any other ethnic group

Please describe

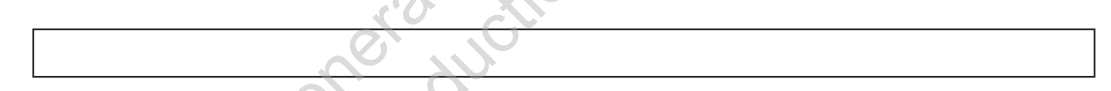

In line with other Health Authorities in the UK, we are required to collect information on the ethnic origin of the children and families for whom we provide services. We collect this information to ensure that we are providing services fairly and equitably to all those who need them.

THANK YOU FOR YOUR HELP

PLEASE RETURN THIS FORM TO US IN THE REPLY-PAID ENVELOPE 